\title{
Microbubble-Mediated Enhanced Delivery of Curcumin to Cervical Cancer Cells
}

\author{
Awaneesh Upadhyay, ${ }^{\dagger, \S(0)}$ Bhrugu Yagnik, ${ }^{\ddagger, \|}$ Priti Desai, ${ }^{+, \perp}$ and Sameer V. Dalvi ${ }^{*}{ }^{\dagger}$ (i) \\ ${ }^{\dagger}$ Chemical Engineering, IIT Gandhinagar, Palaj, Gandhinagar 382355, Gujarat, India \\ ${ }^{\ddagger}$ B.V. Patel Pharmaceutical Education and Research Development (PERD) Centre, Thaltej, Ahmedabad 380054, Gujarat, India
}

\section{Supporting Information}

ABSTRACT: The major bottleneck in the current chemotherapy treatment of cancer is the low bioavailability and high cytotoxicity. Targeted delivery of drug to the cancer cells can reduce the cytotoxicity and increase the bioavailability. In this context, microbubbles are currently being explored as drugdelivery vehicles to effectively deliver drug to the tumors or cancerous cells. Microbubbles when used along with ultrasound can enhance drug uptake and inhibit the growth of tumor cells. Several potential anticancer molecules exhibit poor water solubility, which limits their use in therapeutic

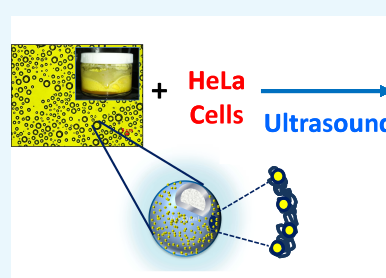

Curcumin-loaded Protein Microbubbles


applications. Such poorly water soluble molecules can be coadministered with microbubbles or encapsulated within or loaded on the microbubbles surface, to enhance the effectiveness of these molecules against cancer cells. Curcumin is one of such potential anticancer molecules obtained from the rhizome of herbal spice, turmeric. In this work, curcumin-loaded protein microbubbles were synthesized and examined for effective in vitro delivery of curcumin to HeLa cells. Microbubbles in the size range of $1-10 \mu \mathrm{m}$ were produced using perfluorobutane as core gas and bovine serum albumin (BSA) as shell material and were loaded with curcumin. The amount of curcumin loaded on the microbubble surface was estimated using UV-vis spectroscopy, and the average curcumin loading was found to be $\sim 54 \mu \mathrm{M} / 10^{8}$ microbubbles. Kinetics of in vitro curcumin release from microbubble surface was also estimated, where a 4-fold increase in the rate of curcumin release was obtained in the presence of ultrasound. Sonication and incubation of HeLa cells with curcuminloaded BSA microbubbles enhanced the uptake of curcumin by $\sim 250$ times. Further, 3-(4,5-dimethylthiazol-2-yl)-2,5diphenyltetrazolium bromide assay confirmed $\sim 71 \%$ decrease in cell viability when HeLa cells were sonicated with curcuminloaded microbubbles and incubated for $48 \mathrm{~h}$.

\section{INTRODUCTION}

Researchers are exploring targeted and efficient delivery of anticancer drug molecules to tumor cells to minimize the damage caused to healthy cells. ${ }^{1}$ Drug carriers such as microbubbles (MBs) can be used to achieve this, as microbubbles have been successfully demonstrated for a localized drug delivery to cancer cells. ${ }^{2-9}$ Microbubbles can be loaded with drug by direct binding to its surface, ${ }^{10}$ binding through ligand, ${ }^{11,12}$ or encapsulating drug/gene inside the gaseous core. ${ }^{13,14}$ Since microbubbles consist of a compressible gaseous core, ultrasound can be used to manipulate the microbubble behavior in aqueous medium, ${ }^{15-18}$ e.g., ultrasound can be used to burst microbubbles, ${ }^{19}$ a phenomenon which can be exploited for local and targeted delivery of drugs/ genes using microbubbles ${ }^{3,5,14}$ or even to deliver drug molecules across the blood-brain barrier. ${ }^{20,21}$ Such strategies help reduce damage caused to the healthy cells.

In this paper, results from studies related to the synthesis of protein microbubbles loaded with curcumin and their effectiveness in enhancing the curcumin uptake by HeLa cells have been reported. Curcumin, a naturally occurring molecule, derived from the rhizome of an herbal spice, turmeric, is known to possess anticancer properties. ${ }^{22-25}$ However, curcumin suffers from poor aqueous solubility and hence low bioavailability. ${ }^{22}$ Therefore, an efficient way of curcumin delivery (such as loading the drug cargo directly on drug-delivery vehicles) needs to be adopted (rather than traditional drug-delivery routes) to enhance its effectiveness against cancer cells. At present, delivery of curcumin to H22 tumors in the form of nanoparticles encapsulated within the core of microbubbles or as a coadministration along with microbubbles (Sonovue) to MDA-MB-231 cancer cells ${ }^{26}$ has been studied. However, in this work, curcumin was directly loaded on the microbubble surface. Microbubbles were synthesized using bovine serum albumin (BSA) as shell material and perfluorobutane (PFB) as core gas. Curcumin uptake by HeLa cells was found to increase, and the cell viability was found to reduce significantly when curcuminloaded BSA microbubbles ( $\mathrm{CuB} \mathrm{MBs}$ ) were used along with ultrasound. This is the first report where microbubbles with

Received: July 21, 2018

Accepted: September 24, 2018

Published: October 8, 2018 

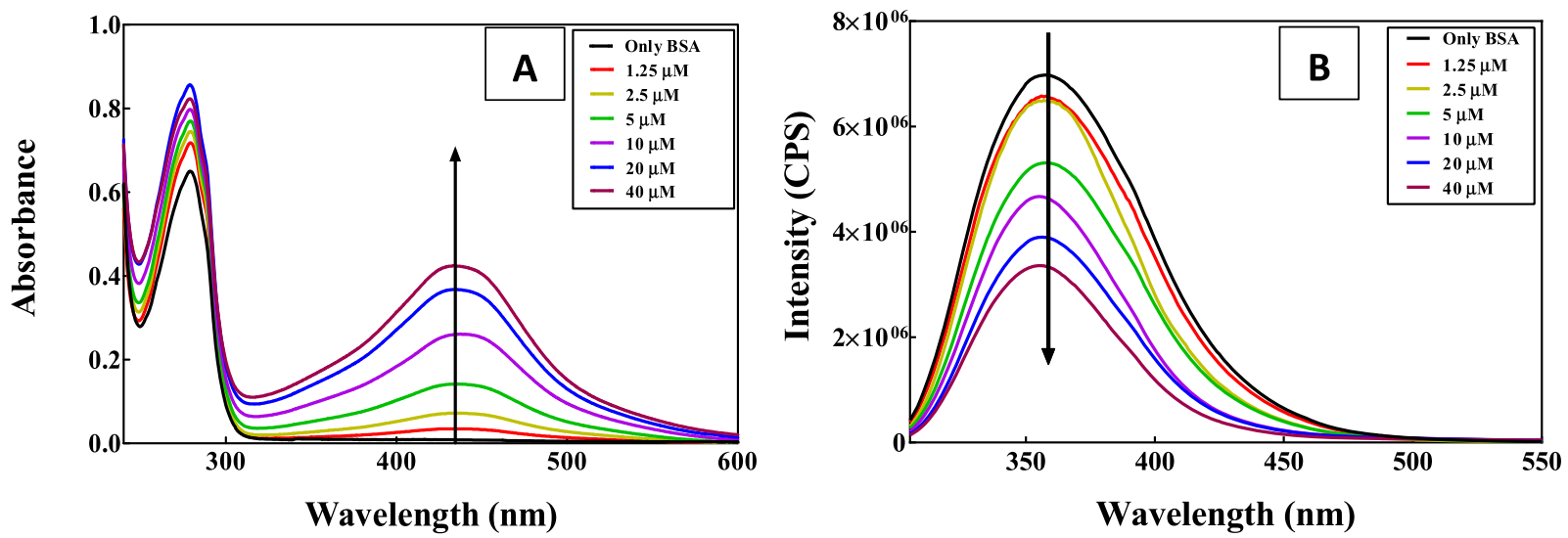

Figure 1. (A) UV absorbance spectra of protein solution containing different curcumin concentrations and (B) fluorescence spectra of protein solution containing different curcumin concentrations.


Figure 2. (A) Optical micrograph and (B) size distribution of curcumin-loaded BSA microbubbles. The inset in (B) shows a photo of curcuminloaded BSA microbubbles suspension.

curcumin loaded on the microbubble surface have been used for delivery of curcumin to HeLa cells. Further, we show that curcumin-loaded microbubbles when combined with ultrasound can significantly reduce the concentration of curcumin needed to decrease the cell viability.

\section{RESULTS AND DISCUSSION}

Interaction between Curcumin and BSA. To verify the complex formation between curcumin and BSA, UV-vis and fluorescence spectrophotometry techniques were used. Figure 1A shows UV-vis spectra for a BSA solution containing varying curcumin concentrations. It can be clearly seen from Figure 1A that each spectrum (except the spectrum for only BSA) contains two distinct peaks, at around 278 and $425 \mathrm{~nm}$, corresponding to BSA and curcumin. ${ }^{27}$ As the concentration of curcumin in the solution increases, the peak intensity corresponding to curcumin as well as BSA increases. The appearance of two distinct peaks in the absorption spectra with an increase in curcumin concentration is an indication of complex formation. ${ }^{27}$ Figure $1 \mathrm{~B}$ shows fluorescence spectra obtained from curcumin-BSA solution. The curcumin spectra are not shown in Figure $1 \mathrm{~B}$ as curcumin does not show any fluorescence at the excitation frequency of $295 \mathrm{~nm} .^{28}$ The spectra (in Figure 1B) show fluorescence emission of BSA molecules, which are mainly attributed to Trp amino acids present in BSA molecule (Trp134 and Trp213) and especially Trp213 present in the hydrophobic cleft. It was observed that the fluorescence intensity decreases with an increase in concentration of curcumin. These changes in fluorescence intensity can be attributed to the interaction of curcumin with BSA. Curcumin molecule enters the hydrophobic cavity of BSA molecule, where Trp213 is present, and then binds with BSA molecule at this position through hydrophobic interactions, which hinders the fluorescence emission. ${ }^{27,29}$

Synthesis and Characterization of Microbubbles. Figure 2A shows optical microscopy image, and Figure 2B shows size distribution of size-isolated $(1-10 \mu \mathrm{m})$ curcuminloaded BSA microbubbles. The size-isolated microbubble population was obtained from freshly prepared polydisperse microbubbles (with size ranging from submicron to $20 \mu \mathrm{m}$ or more) using the differential centrifugation process, as described by Feshitan et al. ${ }^{30}$ These size-isolated $(1-10 \mu \mathrm{m})$ curcumin-loaded BSA microbubbles were then stored in a solution containing curcumin-BSA solution $(80 \% \mathrm{v} / \mathrm{v}), 1,2$ propanediol $(10 \% \mathrm{v} / \mathrm{v})$, and glycerol $(10 \% \mathrm{v} / \mathrm{v})(\mathrm{PGO})$ for further analysis and used in drug uptake and cell culture studies. Long-term stability studies were not carried out for these microbubbles as in our earlier work, ${ }^{31}$ and protein microbubbles were found to be stable for $\sim 8$ months. Further, 
the curcumin-loaded BSA microbubbles were stable for at least 1 day in suspension media.

Estimation of Average Curcumin Loading per Microbubble and in Vitro Release of Curcumin. The amount of curcumin loaded on microbubbles was calculated by the quantification method described in Methods. On the basis of the UV-vis absorbance data, curcumin loading was found to be $\sim 54 \mu \mathrm{M} / 10^{8}$ microbubbles. Figure 3 shows profiles of

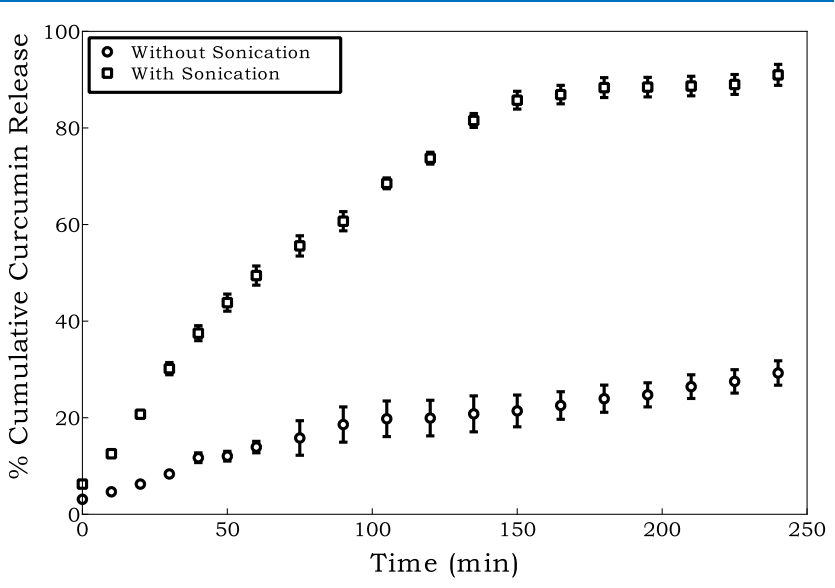

Figure 3. \% Cumulative curcumin release from curcumin-loaded BSA microbubbles in phosphate-buffered saline (PBS) maintained at 37 ${ }^{\circ} \mathrm{C}$. After $60 \mathrm{~min}$, about $50 \%$ of curcumin was released when ultrasound was used, whereas only $\sim 14 \%$ of curcumin was released when ultrasound was not used.

curcumin release from curcumin-loaded BSA microbubbles when microbubbles were mixed with phosphate-buffered saline (PBS) (maintained at $37{ }^{\circ} \mathrm{C}$ ) in the presence and absence of ultrasound. About $50 \%$ of the total curcumin was released within the first $1 \mathrm{~h}$ and roughly $90 \%$ of the curcumin was released from microbubbles by the end of $4 \mathrm{~h}$ when the solution was subjected to ultrasound $\left(1 \mathrm{MHz}, 0.5 \mathrm{~W} / \mathrm{cm}^{2}\right.$, and $5 \mathrm{~s})$. On the other hand, when no ultrasound was used, only $\sim 14 \%$ of curcumin was released in $1 \mathrm{~h}$ and only $\sim 30 \%$ curcumin was released in $4 \mathrm{~h}$ from microbubbles. Thus, it is clear that the use of ultrasound accelerates release of curcumin from the microbubble surface and hence the overall \% curcumin release increases with the use of ultrasound. It should be noted that ultrasound might burst some of the microbubbles and some microbubbles could even dissolve. However, as mentioned in the previous section, most of the microbubbles remain stable over a long period of time.

In Vitro Curcumin Uptake by HeLa Cells. As stated in Methods, the operating parameters were optimized for maximum drug uptake by HeLa cells. Figure 4 shows the variation in drug uptake by HeLa cells when three different cell-to-microbubbles ratios, viz., 100:1, 1:1, and 1:100, and six sonication exposure times, viz., 5, 10, 15, 20, 25, and $30 \mathrm{~s}$, were used.

HeLa cells were mixed with microbubbles, sonicated, and were incubated for $24 \mathrm{~h}$. Ultrasound with $1 \mathrm{MHz}$ frequency and $1.5 \mathrm{~W} / \mathrm{cm}^{2}$ intensity was used and sonication was carried out for 5, 10, 15, 20, 25, and 30 s. It can be observed in Figure 4 that curcumin uptake increases at all ultrasonic exposure times with a decrease in cell-to-microbubble ratio. This can be attributed to an increase in the curcumin payload as a decrease in cell-to-microbubble ratio increases microbubble number per cell. It should also be noted that the values of fluorescence in

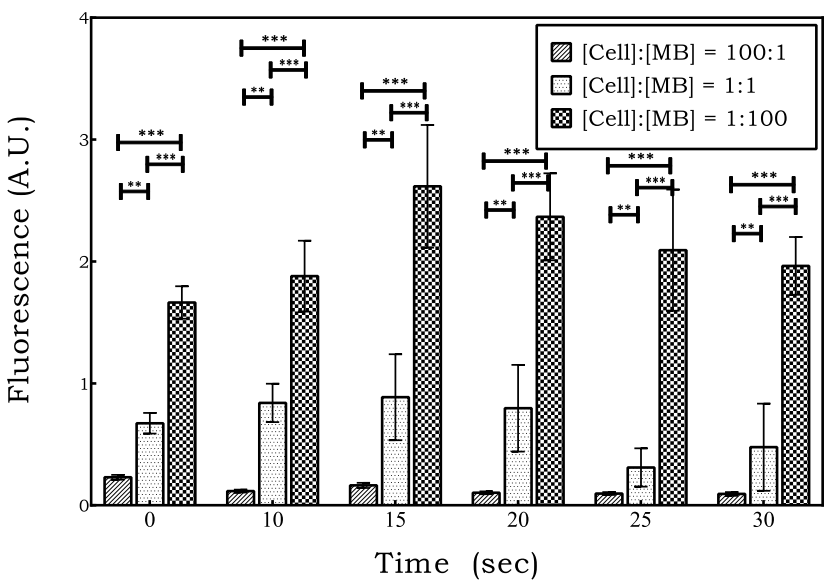

Figure 4. Variation in curcumin uptake by HeLa cells when $\sim 10^{6}$ cells were treated with varying concentrations of curcumin-loaded BSA microbubbles (CuB MBs) (100:1, 1:1, and 1:100) and varying ultrasonic exposure times. Data in the above figure are means \pm standard deviation (SD) of three independent experiments. The error bars are two-tailed, where $* * p<0.005, * * * p<0.0004$.

Figure 4 are low. This could be attributed to the cell death due to sonication at an intensity of $1.5 \mathrm{~W} / \mathrm{cm}^{2}$. Since the fluorescence measured corresponds to live cells only, the values of fluorescence reported in Figure 4 are low. However, a maximum curcumin uptake was obtained at a cell-tomicrobubbles ratio of $1: 100$, and hence, all further experiments were conducted at this ratio.

Figure 5 shows a variation in curcumin uptake by HeLa cells when they were exposed to different ultrasound intensities $(0$, $0.5,1$, and $\left.1.5 \mathrm{~W} / \mathrm{cm}^{2}\right)$ at varying exposure times $(5,10$, and $15 \mathrm{~s})$. The cell-to-microbubble ratio was kept constant at 1:100. It can be observed from Figure 5 that the curcumin uptake was maximum at the ultrasound intensity of $0.5 \mathrm{~W} / \mathrm{cm}^{2}$ and exposure time of $5 \mathrm{~s}$. Further, it can also be observed that an increase in ultrasonic intensity beyond $0.5 \mathrm{~W} / \mathrm{cm}^{2}$ decreases the amount of drug uptake by the cells. This could be attributed to the likely cell death by ultrasound at ultrasonic intensities higher than $0.5 \mathrm{~W} / \mathrm{cm}^{2}$. The cell samples were washed (as per standard protocol) before the analysis, resulting in the washing out of the dead cells, which did not adhere to the walls of wells in the cell culture plate. Since only live cells were analyzed for cellular uptake, the overall uptake shows a decrease in total curcumin uptake.

On the basis of these observations, the final curcumin uptake experiment was conducted at the following optimized parameters: cell-to-microbubble ratio, 1:100; ultrasonic intensity, $0.5 \mathrm{~W} / \mathrm{cm}^{2}$; and ultrasonic exposure time, $5 \mathrm{~s}$. Figure 6 shows relative fluorescence of the curcumin uptake by HeLa cells. The untreated HeLa cells (no ultrasound, no curcumin, and no microbubbles) were used as control. It can be observed from Figure 6 that the uptake of curcumin in the case of HeLa cells sonicated with a mixture of aqueous solution of curcumin and BSA microbubbles was found to be about $~ 3$-fold higher than that for HeLa cells sonicated only with aqueous solution of curcumin (no microbubbles). The uptake of curcumin increases significantly, by $\sim 250$-folds when HeLa cells $\left(\sim 10^{6}\right)$ were sonicated with curcumin-loaded microbubbles. This indicates that curcumin-loaded BSA microbubbles are highly effective than the bare (unloaded) microbubbles coadministered with curcumin solution in enhancing the uptake of curcumin by HeLa cells. Further, it should be noted that the 


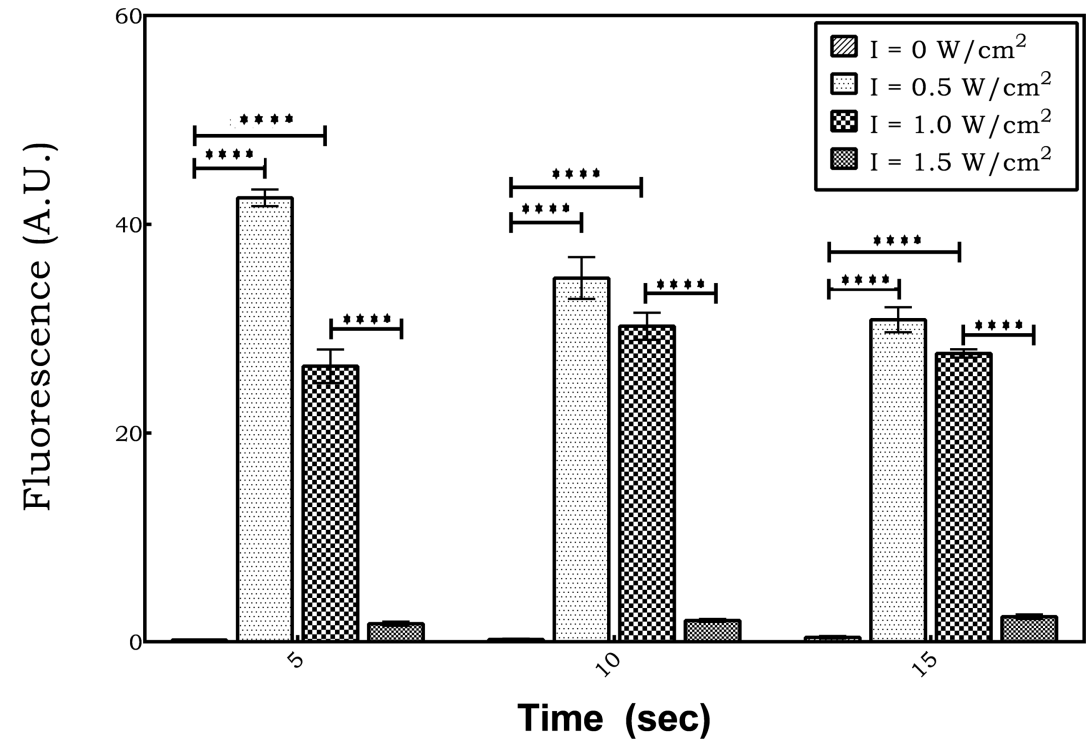

Figure 5. Variation in curcumin uptake by HeLa cells when $\sim 10^{6}$ cells were treated with $\sim 10^{8}$ curcumin-loaded BSA microbubbles (cell-tomicrobubble ratio of 1:100) with varying ultrasonic intensity and sonication time. Data in above figure are means \pm SD of three independent experiments. All of the error bars are two-tailed. $* * * *<0.0001$ compared to respective control data set $\left(\right.$ at $\left.I=0 \mathrm{~W} / \mathrm{cm}^{2}\right)$.

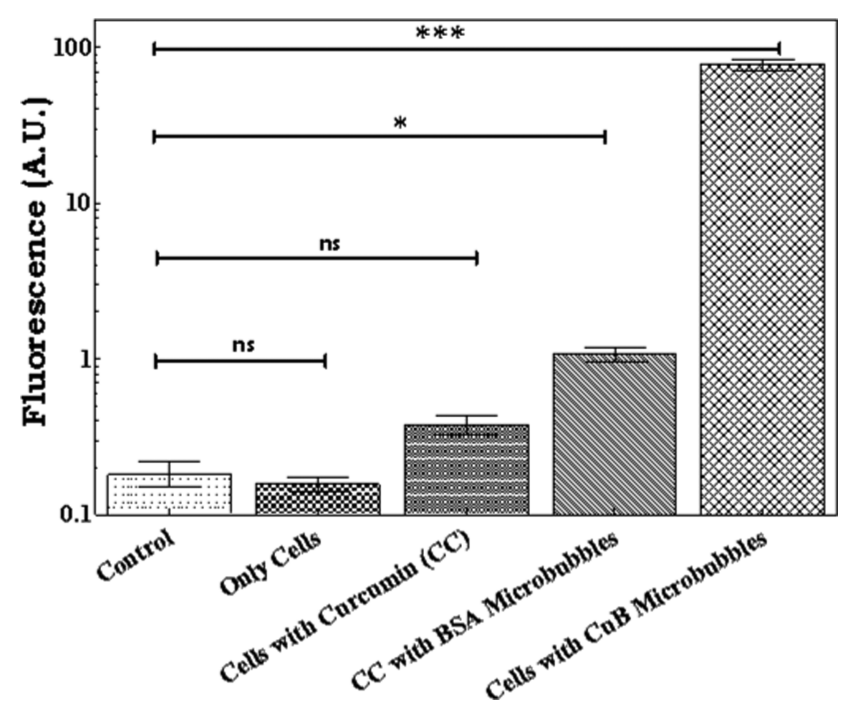

Figure 6. Variation in curcumin uptake by HeLa cells. Sonication with intensity of $0.5 \mathrm{~W} / \mathrm{cm}^{2}$ and exposure time of $5 \mathrm{~s}$ was used for all samples except control. Cell-to-microbubble ratio used was 1:100. The cells were incubated for $24 \mathrm{~h}$ with different samples. Control indicates untreated HeLa cells (no ultrasound, no curcumin, and no microbubbles), only cells indicates sonicated HeLa cells (treated with ultrasound but no curcumin or microbubbles), and $\mathrm{CuB}$ indicates curcumin-loaded BSA microbubbles. Data are means \pm SD of three independent experiments. The error bars are two-tailed. ${ }^{*} p<0.05$, $* * * p<0.001$ and $\mathrm{ns}$ means nonsignificant compared to control.

values of fluorescence due to curcumin uptake reported in Figure 6 are higher than the values reported in Figures 4 and 5 . This could be because the curcumin uptake experiments reported in Figure 6 were conducted at the optimum conditions of US intensity $\left(0.5 \mathrm{~W} / \mathrm{cm}^{2}\right)$ and cell-to-microbubble ratio (1:100), where the highest curcumin uptake was observed (as presented in Figures 4 and 5).

Sonication of cells in the presence of microbubbles results in sonoporation of the cell membrane. The pores generated in the cell membrane by sonoporation are mostly transient and re- seal within $\sim 20$ s. $^{32}$ The drug uptake therefore has to take place within this short time. Sonicating HeLa cells with only curcumin solution does not result in a higher curcumin uptake since curcumin molecules have to diffuse through the surrounding medium as well as cell cytoplasm when the pores are open for a very short duration. The slow process of diffusion and quick re-sealing of sonoporated cell membrane result in a lower uptake of curcumin. However, in the case of curcumin-loaded BSA microbubbles, the rupture of curcuminloaded microbubbles results in a higher curcumin concentration just next to the cell wall. Sonoporation of cell membrane followed by quick diffusion of these large number of available curcumin molecules along with tiny fragments of microbubbles shell loaded with curcumin molecules results into a quick and higher curcumin uptake by HeLa cells. ${ }^{10,33}$

In Vitro Cell Viability of HeLa Cells. Figure 7 presents variation in $\%$ cell viability when $\mathrm{HeLa}$ cells were sonicated with only curcumin solution, a mixture of curcumin solution and BSA microbubbles, and curcumin-loaded BSA microbubbles. HeLa cells without any treatment were considered as a control. All of the samples except the control were subjected to sonication. The cells were incubated for $48 \mathrm{~h}$ after sonication. 3-(4,5-Dimethylthiazol-2-yl)-2,5-diphenyltetrazolium bromide (MTT) assay was used to estimate \% cell viability. As is evident from Figure 7, when only sonication was used, cell viability reduced to $\sim 66 \%$. Further reduction in cell viability was obtained for HeLa cells sonicated with only curcumin solution (in Dulbecco's modified Eagle's medium (DMEM)). In this case, the viability of HeLa cells was found to reduce to $\sim 51 \%$. A significant decrease in cell viability (about a $71 \%$ decrease in live cells) was obtained when cells were sonicated with curcumin-loaded BSA microbubbles (Figure 7). To achieve the similar reduction in cell viability, about $100 \mu \mathrm{M}$ of curcumin would be needed if only curcumin (no microbubbles) is used (see Figure S1).

Thus, it is clear that curcumin-loaded microbubbles when combined with ultrasound can significantly reduce the concentration of curcumin needed to decrease the cell viability. This could be attributed to the curcumin-loaded microbubbles 


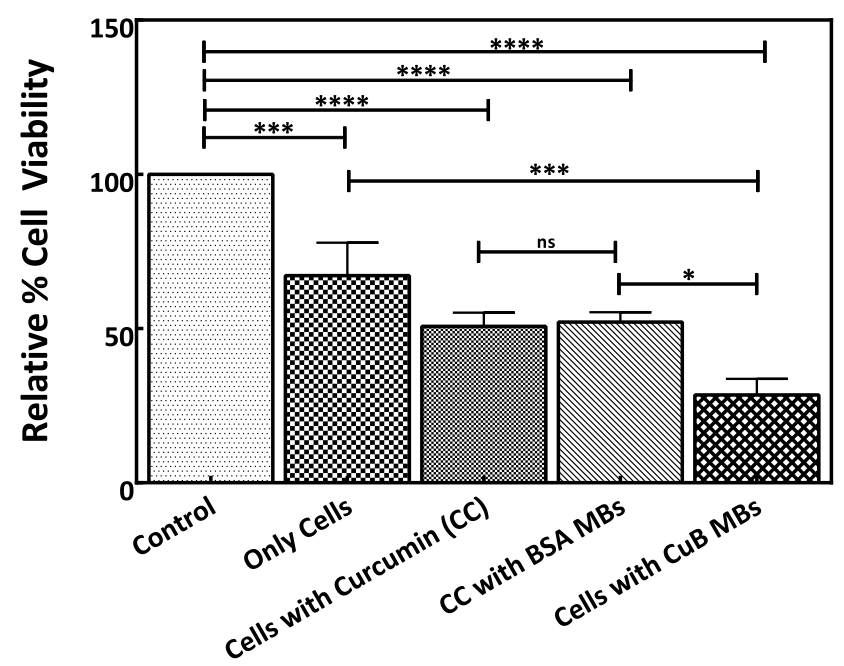

Figure 7. Cell viability of HeLa cells when subjected to curcumin and microbubbles samples (cell-to-microbubble ratio, 1:100) and incubated for $48 \mathrm{~h}$. Control indicates untreated (no ultrasound, no curcumin, and no microbubbles) HeLa cells, only cells indicates sonicated HeLa cells (but no curcumin or microbubbles), and $\mathrm{CuB}$ indicates curcumin-loaded BSA microbubbles. All of the samples except the control were subjected to sonication for $5 \mathrm{~s}$ at an intensity of $0.5 \mathrm{~W} / \mathrm{cm}^{2}$. Data are means $\pm \mathrm{SD}$ of three independent experiments. The error bars are two-tailed. $*_{p}<0.05$, $*_{* *} *_{p}<$ 0.0005 and $* * * * p<0.0001$ and ns means nonsignificant.

being much more efficient in enhancing the drug uptake due to their rupture upon exposure to ultrasound, thereby reducing the cell viability

\section{CONCLUSIONS}

Curcumin-loaded BSA microbubbles were synthesized using aqueous ethanolic solution containing BSA and curcumin and PFB as core gas. The curcumin-BSA conjugation was confirmed through fluorescence and UV-vis studies. A probe sonication technique was used to prepare a polydisperse microbubble suspension, and a differential centrifugation technique was used to obtain a narrow-sized microbubble population in the range of $1-10 \mu \mathrm{m}$ (in diameter). The amount of curcumin loaded on microbubbles was estimated using UV-vis spectrophotometry and was found to be $\sim 54$ $\mu \mathrm{M} / 10^{8}$ microbubble. The kinetics of in vitro curcumin release in PBS (heated at $37^{\circ} \mathrm{C}$ ) from curcumin-loaded microbubbles was also estimated. About $50 \%$ of curcumin was released in $1 \mathrm{~h}$ and $\sim 90 \%$ curcumin within $4 \mathrm{~h}$ when microbubbles were subjected to ultrasound. On the other hand, only $14 \%$ of curcumin was released in the first $1 \mathrm{~h}$ and $30 \%$ curcumin was released in $4 \mathrm{~h}$ when ultrasound was not used. Curcumin uptake studies confirmed that microbubbles along with ultrasound can effectively enhance the curcumin uptake by HeLa cells. The curcumin uptake was enhanced by $\sim 250$ times when HeLa cells were subjected to ultrasound in the presence of curcumin-loaded microbubbles compared to HeLa cells sonicated only with curcumin solution. In vitro cell viability studies showed that curcumin-loaded BSA microbubbles were highly effective in reducing cell viability. Only about $29 \%$ HeLa cells survived after $48 \mathrm{~h}$ when treated with curcuminloaded BSA microbubbles and ultrasound. Thus, in this work, we have shown that a curcumin-loaded protein (BSA) microbubble formulation can be used along with ultrasound to efficiently deliver a low bioavailable drug to HeLa cells.

\section{MATERIALS}

BSA, N-acetyl-DL-tryptophan (Tryp), and curcumin were purchased from Sigma-Aldrich, India. Perfluorobutane (PFB) gas was purchased from SynQuest Laboratories. Phosphate buffer tablets were bought from Sigma-Aldrich, India, to prepare a $10 \mathrm{mM}$ phosphate-buffered saline (PBS) solution. HeLa cells were obtained from National Center for Cell Science, Pune, India. Fetal bovine serum, trypsin phosphate versene glucose (TPVG), and Dulbecco's modified Eagle's medium (DMEM) were bought from Gibco. Corning 6-well and 96-well cell culture plates (transparent and black), 3-(4,5dimethylthiazol-2-yl)-2,5-diphenyltetrazolium bromide (MTT), dimethyl sulfoxide (DMSO), and methanol were purchased from Sigma-Aldrich, India. All of the plastic wares used for cell culture work (6-well, 96-well plates, scrapper, and $25 \mathrm{~cm}^{2}$ flasks) were purchased from Corning, and SigmaAldrich, India.

\section{METHODS}

Understanding Curcumin-BSA Interaction. Curcumin solutions with different molar concentrations $(1.25-40 \mu \mathrm{M})$ were prepared in ethanol. A protein solution containing BSA $(30 \mathrm{mg} / \mathrm{mL})$ and Tryp $(9.8 \mathrm{mg} / \mathrm{mL})$ in PBS was used as a base medium. Ethanolic solution of curcumin and BSA solution in PBS were mixed in 5:95 (v/v) ratio to avoid precipitation of curcumin particles. The curcumin-BSA mixture was stirred continuously for around $4 \mathrm{~h}$. These solutions were then centrifuged at $14000 \mathrm{rpm}$ for $10 \mathrm{~min}$ and vacuum-filtered to obtain yellowish transparent solutions.

Interaction of curcumin with BSA was investigated by UV absorption and fluorescence spectroscopy. Protein solutions without and with different curcumin concentrations were analyzed using a Shimadzu UV-vis spectrophotometer. Fluorescence emission studies were also carried out on a Horiba Jobin Yvon Fluorolog-3 spectrofluorometer with a slit width of $1 \mathrm{~nm}$. The protein solution was analyzed for changes in fluorescence spectra with an excitation frequency of $295 \mathrm{~nm}$, while emission spectra were collected between 310 and 500 $\mathrm{nm}$ with an optical path length of $1 \mathrm{~cm}$. The excitation frequency of $295 \mathrm{~nm}$ was used mainly to detect fluorescence emission of tryptophan amino acids (Trp134 and Trp213) present in BSA molecules. Since binding site for curcumin on BSA molecule is also in the vicinity of Trp $213,{ }^{24,34}$ any change in fluorescence of BSA can be attributed to the curcumin interaction with the BSA molecule. ${ }^{27}$

Production of Curcumin-Loaded Microbubbles. Protein microbubbles were produced using a solution of BSA (30 $\mathrm{mg} / \mathrm{mL})$ and $N$-acetyl-DL-tryptophan (Tryp) $(9.8 \mathrm{mg} / \mathrm{mL}$ ) dissolved in $30 \mathrm{~mL}$ of $10 \mathrm{mM}$ PBS. ${ }^{31,35}$ This protein solution was mixed vigorously using a magnetic stirrer until all of the added Tryp dissolved completely and solution turned transparent. An excess of curcumin (about $100 \mathrm{mg} / \mathrm{mL}$ ) was added to ethanol and stirred continuously for about $1 \mathrm{~h}$. Undissolved curcumin was removed from the solution by centrifuging at 14 $000 \mathrm{rpm}$ for $30 \mathrm{~min}$ and the infranatant was filtered using a syringe filter to obtain a clear solution. This solution was then added slowly to the protein solution to maintain a volume ratio of 5:95. This ratio was chosen as it does not precipitate curcumin in the solution. This BSA-curcumin solution was then stirred for around $4 \mathrm{~h}$ at $500 \mathrm{rpm}$. No precipitation of curcumin or BSA was observed and a clear transparent solution was obtained. The solution was heated up to $\sim 69{ }^{\circ} \mathrm{C}$ under 
continuous moderate stirring $(\sim 500 \mathrm{rpm})$. A probe of halfinch diameter (VC 750 Sonics) was placed at the surface of the heated solution and operated at $100 \%$ amplitude for ca. 8-10 s with PFB gas being flown over the solution. The sonication produced a yellowish milky suspension containing microbubbles and foam. This suspension was immediately air-sealed and kept in an ice bath $\left(4^{\circ} \mathrm{C}\right)$ for nearly $30 \mathrm{~min}$. The microbubble suspension was analyzed for size distribution and concentration using Accusizer 780 AD (PSS NICOMP). The as-prepared microbubble suspension was polydisperse in nature and contained microbubbles with size (diameter) varying from submicron scale $(<1 \mu \mathrm{m})$ to more than $20 \mu \mathrm{m}$. This suspension was subjected to centrifugal size isolation ${ }^{29,30}$ to obtain microbubble suspension with a size range of $1-10$ $\mu \mathrm{m}$. To size-isolate the microbubbles, a freshly prepared polydisperse microbubble suspension was collected in $30 \mathrm{~mL}$ syringes and was subjected to centrifugation at $300 \mathrm{rcf}$ for 3 min. The microbubble cake thus obtained was diluted with PBS (to a total volume of $30 \mathrm{~mL}$ ) and centrifuged at $60 \mathrm{rcf}$ for $1 \mathrm{~min}$ to remove microbubbles smaller than $1 \mu \mathrm{m}$ (in infranatant). The resultant cake (with microbubbles of size larger than $1 \mu \mathrm{m}$ ) was diluted with PBS (to a total volume of $30 \mathrm{~mL}$ ) and subjected to $70 \mathrm{rcf}$ for $1 \mathrm{~min}$. The infranatant obtained after this step (which contains microbubbles $<10$ $\mu \mathrm{m}$ ) was subjected to centrifugation at $90 \mathrm{rcf}$ for $1 \mathrm{~min}$ to obtain a cake containing microbubble population with size ranging between 1 and $10 \mu \mathrm{m}$. This cake was then resuspended in $2 \mathrm{~mL}$ of PBS to obtain a microbubble suspension with $1-10$ $\mu \mathrm{m}$ microbubbles and analyzed for size distribution and concentration using Accusizer 780 AD (PSS NICOMP).

Quantification of Curcumin-Loaded on the Microbubble Surface. Curcumin-BSA microbubbles $\left(\sim 10^{8} \mathrm{MBs}\right)$ were added to $1 \mathrm{~mL}$ of ethanol and centrifuged at $14000 \mathrm{rpm}$ for $10 \mathrm{~min}$. Addition of ethanol dissolves curcumin loaded on the microbubble surface. Curcumin concentration in ethanol was estimated by measuring UV absorbance (at $425 \mathrm{~nm}$ ) of the supernatant obtained after centrifugation.

In Vitro Curcumin Release from Microbubbles. The kinetics of curcumin release from microbubble (MB) surface, with and without sonication, was studied by UV-vis spectrophotometry for sonicated and nonsonicated samples. Two sets of samples containing $5 \times 10^{8}$ curcumin-loaded BSA microbubbles in $5 \mathrm{~mL}$ of PBS solution (maintained at $37^{\circ} \mathrm{C}$ ) were prepared by adding a calculated amount of microbubbles from a microbubble suspension containing about $10^{9}$ microbubbles $/ \mathrm{mL}$. One set of sample was sonicated at an ultrasonic intensity of $0.5 \mathrm{~W} / \mathrm{cm}^{2}$ for $5 \mathrm{~s}$ using Electroson 608 ultrasonic system with $1 \mathrm{MHz}$ mean frequency in 1:1 pulse mode $(2 \mathrm{~ms}$ ON and 2 ms OFF cycle). The other set of sample, having the same number of curcumin-loaded BSA microbubbles, was not subjected to sonication. Around $20 \mu \mathrm{L}$ of sample was pipetted out from each of the above solutions at an interval of $15 \mathrm{~min}$ and was analyzed by UV-vis spectroscopy. At the same time, $20 \mu \mathrm{L}$ of stock PBS solution was added back into the solution to maintain the volume of solution constant. In vitro release studies were conducted for about $5 \mathrm{~h}$.

Uptake of Curcumin by HeLa Cells. Around $0.5 \times 10^{6}$ HeLa cells were seeded in six-well plates and incubated for 24 $\mathrm{h}$ at $37{ }^{\circ} \mathrm{C}$ in a humidified atmosphere with a continuous supply of $5 \% \mathrm{CO}_{2}$. Optimization of operating parameters such as cell-to-microbubble concentration ratio, ultrasonic intensity, and ultrasonic exposure time was carried out using curcumin uptake by HeLa cells. Three different cell-to-curcumin-loaded
BSA (CuB) MB ratios (100:1, 1:1, and 1:100) were used. All of these samples except control were sonicated at ultrasonic intensities of $0.5,1$, and $1.5 \mathrm{~W} / \mathrm{cm}^{2}$ and ultrasonic exposure times of 5, 10 and $15 \mathrm{~s}$. HeLa cells without microbubbles and without sonication were used as control. After treatment, the samples were incubated further for $24 \mathrm{~h}$.

Following the incubation, the cells were washed with PBS and treated with $1 \mathrm{~mL}$ of TPVG for $2 \mathrm{~min}$. TPVG was decanted, $1 \mathrm{~mL}$ of PBS was added to each well, and the cells were collected using scrappers in $2 \mathrm{~mL}$ centrifuge vials. The cells were centrifuged at $1500 \mathrm{~g}$ for $10 \mathrm{~min}$, and the supernatant was discarded. The cell pellet obtained was resuspended in 500 $\mu \mathrm{L}$ of methanol and subjected to a probe sonication cycle of 10 $\mathrm{s}$ ON/20 s OFF three times for cell lysis and to extract curcumin in methanol solution. The lysed cell solution was further centrifuged at $1500 \mathrm{~g}$ for $10 \mathrm{~min}$, and the supernatant was transferred to Thermo Fisher Nunc flat-bottom 96-well black polystyrene plates. The fluorescence intensity was measured using a Thermo Fisher Varioskan Flash multimode reader with an emission wavelength of $570 \mathrm{~nm}$. Cells without curcumin-loaded BSA microbubbles and without sonication were used as controls.

To estimate the actual curcumin uptake by HeLa cells in the presence of curcumin-loaded BSA microbubbles and therapeutic ultrasound, a similar procedure was adopted. HeLa cells were incubated (in six-well plate) with different samples, namely, curcumin dissolved in DMEM (saturated solution), saturated curcumin solution with only BSA MBs, and curcumin-loaded BSA microbubbles. The number of microbubbles in each sample was kept constant at $10^{8} /$ well. Further, the amount of curcumin in each sample was kept constant at $54 \mu \mathrm{M}$ (equal to the amount of curcumin loaded on $10^{8}$ curcumin-loaded BSA ( $\mathrm{CuB})$ microbubbles). For each of the above samples, two different cell culture plates were prepared. One plate was subjected to sonication and was labeled as treated. The other plate was not subjected to ultrasound and was labeled as untreated. The optimized operating parameters such as cell-to-curcumin-loaded BSA microbubble ratio of $1: 100$, ultrasonic intensity of $0.5 \mathrm{~W} / \mathrm{cm}^{2}$, and ultrasonic exposure time of $5 \mathrm{~s}$ were used during these experiments. The treated and untreated cells were then incubated for $24 \mathrm{~h}$ and analyzed as explained in the above paragraph to estimate curcumin uptake by the HeLa cells.

In Vitro Cell Viability Assay. Curcumin-loaded BSA microbubbles were evaluated for their cytotoxicity on HeLa cells using MTT assay protocol as described earlier. Microbubble concentration added to different wells was kept constant at $\sim 10^{6} \mathrm{MBs} /$ well for all formulations (to maintain a cell-to-microbubble ratio of $1: 100)$. The concentration of curcumin in each sample was also kept constant at $\sim 0.54 \mu \mathrm{M}$ (which corresponds to the concentration of curcumin loaded on surface of $\sim 10^{6}$ microbubbles). Also, about $10 \mu \mathrm{M}$ curcumin dissolved in DMSO was added to each well to increase the overall concentration of curcumin. Two sets of cell culture samples were prepared in a manner similar to that discussed in "Uptake of Curcumin by HeLa Cells". After an incubation period of $24 \mathrm{~h}$, when cell confluency was $~ 90 \%$, microbubbles were added to the wells of cell culture plates. While one plate was sonicated (labeled as treated) for $5 \mathrm{~s}$ at an intensity of $0.5 \mathrm{~W} / \mathrm{cm}^{2}$, the other plate was not sonicated (labeled as untreated). The cell culture plates were then kept for incubation for $48 \mathrm{~h}$ at $37^{\circ} \mathrm{C}$ in a humidified atmosphere with $5 \% \mathrm{CO}_{2}$ supply. 
After incubation, the plates (treated and untreated) were washed with phosphate-buffered saline (PBS) and $\sim 200 \mu \mathrm{L}$ of MTT solution $(5 \mathrm{mg} / \mathrm{mL})$ was added to each well. The cells were then incubated at $37{ }^{\circ} \mathrm{C}$ in the dark for $3 \mathrm{~h}$. Following incubation, the plates were centrifuged at $1500 \mathrm{~g}$ for $10 \mathrm{~min}$ at room temperature. The supernatant was removed following the incubation, and $200 \mu \mathrm{L}$ of DMSO was added to each well. The cell viability was calculated following UV-vis absorbance at $570 \mathrm{~nm}$.

Statistical Analysis. The statistical analysis was performed on the experimental mean data obtained from at least three independent observations. The standard deviations are shown as error bars $( \pm)$ in respective figures. The comparison between two mean values for statistical significance was made by performing a one-way analysis of variance.

\section{ASSOCIATED CONTENT}

\section{S Supporting Information}

The Supporting Information is available free of charge on the ACS Publications website at DOI: 10.1021/acsomega.8b01737.

Effect of curcumin on HeLa cell viability; materials; experimental procedure; results and discussion; effect of curcumin on viability of HeLa cells (Figure S1) (PDF)

\section{AUTHOR INFORMATION}

\section{Corresponding Author}

*E-mail: sameervd@iitgn.ac.in.

\section{ORCID $\odot$}

Awaneesh Upadhyay: 0000-0001-5930-2028

Sameer V. Dalvi: 0000-0001-5262-8711

\section{Present Addresses}

${ }^{\perp}$ School of Biological Sciences \& Biotechnology, University and Institute of Advanced Research Institutional Area, Koba, Gandhinagar 382426, Gujarat, India (P.D.).

"Yerkes National Primate Research Centre, Emory University, Atlanta, Georgia 30322, United States (B.Y.).

${ }^{\S}$ Mechanical Engineering, University of Colorado at Boulder, Colorado 80309, United States (A.U.).

\section{Funding}

This work was supported by grants from Department of Biotechnology (DBT) (Grant No: BT/PR15323/MED/32/ 162/2011) of Government of India, Indian Institute of Technology Gandhinagar (IITGN), and the Center for Biomedical Engineering at IITGN.

\section{Notes}

The authors declare no competing financial interest.

\section{ACKNOWLEDGMENTS}

The authors thank Dr Manish Nivsarkar, Director, B.V. Patel Pharmaceutical Education and Research Development Centre (PERD), Ahmedabad, for allowing them to conduct cell line studies at PERD. The authors also thank Dr Nirav Desai and Dr Avani from Cadila Pharmaceuticals for helping them with the MTS assay studies. The authors would also like to thank Drashya and Ashish from Cell and Molecular Biology Lab, BVPERD Centre, Ahmedabad, for their help in facilitating cell culture studies.

\section{REFERENCES}

(1) Lee, M.; Ping, M.; Johnson, K.; Mumper, R. J.; Dayton, P. A. Tumor Treatment with Microbubble Enhanced Low-Intensity Ultrasound and Paclitaxel Nanocapsules Reduces Drug Dose Required for Therapeutic Effect. IEEE International Ultrasonics Symposium (IUS); IEEE: Orlando, 2011; pp 1455-1458.

(2) Chitnis, P. V.; Koppolu, S.; Mamou, J.; Chlon, C.; Ketterling, J. A. Influence of Shell Properties on High-Frequency Ultrasound Imaging and Drug Delivery Using Polymer-Shelled Microbubbles. IEEE Trans. Ultrason. Ferroelectrics Freq. Contr. 2013, 60, 53-64.

(3) Ferrara, K.; Pollard, R.; Borden, M. Ultrasound Microbubble Contrast Agents: Fundamentals and Application to Gene and Drug Delivery. Annu. Rev. Biomed. Eng. 2007, 9, 415-447.

(4) Geers, B.; Lentacker, I.; Sanders, N. N.; Demeester, J.; Meairs, S.; De Smedt, S. C. Self-assembled liposome-loaded microbubbles: The missing link for safe and efficient ultrasound triggered drugdelivery. J. Controlled Release 2011, 152, 249-256.

(5) Hernot, S.; Klibanov, A. Microbubbles in ultrasound-triggered drug and gene delivery. Adv. Drug Delivery Rev. 2008, 60, 1153-1166.

(6) Liu, Y.; Miyoshi, H.; Nakamura, M. Encapsulated ultrasound microbubbles: Therapeutic application in drug/gene delivery. J. Controlled Release 2006, 114, 89-99.

(7) Unger, E. C.; Hersh, E.; Vannan, M.; Matsunaga, T. O.; McCreery, T. Local drug and gene delivery through microbubbles. Prog. Cardiovasc. Dis. 2001, 44, 45-54.

(8) Wu, D.; Wan, M. A novel ultrasonic-triggered drug release and tracked drug delivery system based on gas-filled BSA microbubbles and gelatin nanogels. J. Controlled Release 2015, 213, No. e24.

(9) Yan, F.; Li, L.; Deng, Z.; Jin, Q.; Chen, J.; Yang, W.; Yeh, C.-K.; Wu, J.; Shandas, R.; Liu, X.; Zheng, H. Paclitaxel-liposomemicrobubble complexes as ultrasound-triggered therapeutic drug delivery carriers. J. Controlled Release 2013, 166, 246-255.

(10) Lentacker, I.; De Smedt, S. C.; Sanders, N. N. Drug loaded microbubble design for ultrasound triggered delivery. Soft Matter 2009, 5, 2161-2170.

(11) Klibanov, A. L. Ligand-Carrying Gas-Filled Microbubbles: Ultrasound Contrast Agents for Targeted Molecular Imaging. Bioconjugate Chem. 2005, 16, 9-17.

(12) Cavalieri, F.; El Hamassi, A.; Chiessi, E.; Paradossi, G.; Villa, R.; Zaffaroni, N. Tethering Functional Ligands onto Shell of Ultrasound Active Polymeric Microbubbles. Biomacromolecules 2006, 7, 604-611.

(13) Chen, H.; Hwang, J. H. Ultrasound-targeted microbubble destruction for chemotherapeutic drug delivery to solid tumors. J. Ther. Ultrasound 2013, 1, No. 10.

(14) Wang, X.; Liang, H.-D.; Dong, B.; Lu, Q.-L.; Blomley, M. J. K. Gene Transfer with Microbubble Ultrasound and Plasmid DNA into Skeletal Muscle of Mice: Comparison between Commercially Available Microbubble Contrast Agents. Radiology 2005, 237, 224229.

(15) de Jong, N.; Frinking, P. J. A.; Bouakaz, A.; Ten Cate, F. J. Detection procedures of ultrasound contrast agents. Ultrasonics 2000, $38,87-92$.

(16) Correas, J.-M.; Bridal, L.; Lesavre, A.; Méjean, A.; Claudon, M.; Hélénon, O. Ultrasound contrast agents: properties, principles of action, tolerance, and artifacts. Eur. Radiol. 2001, 11, 1316-1328.

(17) Leong-Poi, H.; Song, J.; Rim, S.-J.; Christiansen, J.; Kaul, S.; Lindner, J. R. Influence of microbubble shell properties on ultrasound signal: Implications for low-power perfusion imaging. J. Am. Soc. Echocardiogr. 2002, 15, 1269-1276.

(18) Chatterjee, D.; Jain, P.; Sarkar, K. Ultrasound-mediated destruction of contrast microbubbles used for medical imaging and drug delivery. Phys. Fluids 2005, 17, No. 100603.

(19) Tsutsui, J. M.; Xie, F.; Porter, R. T. The use of microbubbles to target drug delivery. Cardiovasc. Ultrasound 2004, 2, No. 23.

(20) Choi, J. J.; Feshitan, J. A.; Baseri, B.; Shougang, W.; Yao-Sheng, T.; Borden, M. A.; Konofagou, E. E. Microbubble-Size Dependence of Focused Ultrasound-Induced Blood Brain Barrier Opening in Mice In Vivo. IEEE Trans. Biomed. Eng. 2010, 57, 145-154. 
(21) Wu, S.-Y.; Chen, C. C.; Tung, Y.-S.; Olumolade, O. O.; Konofagou, E. E. Effects of the microbubble shell physicochemical properties on ultrasound-mediated drug delivery to the brain. $J$. Controlled Release 2015, 212, 30-40.

(22) Ji, G.; Yang, J.; Chen, J. Preparation of novel curcumin-loaded multifunctional nanodroplets for combining ultrasonic development and targeted chemotherapy. Int. J. Pharm. 2014, 466, 314-320.

(23) Jithan, A.; Madhavi, K.; Madhavi, M.; Prabhakar, K. Preparation and characterization of albumin nanoparticles encapsulating curcumin intended for the treatment of breast cancer. Int. J. Pharm. Invest. 2011, $1,119-125$.

(24) Kooshka, M. R. A.; Mansouria, K.; MostafaNadib, M.; Khodarahmia, S.; Khodarahmi, R. In Vitro Anti-Cancer Activity of Native Curcumin and "Protein-Curcumin" Systems: A Perspective on Drug-Delivery Application. J. Rep. Pharm. Sci. 2013, 2, 80-88.

(25) Kunnumakkara, A. B.; Guha, S.; Krishnan, S.; Diagaradjane, P.; Gelovani, J.; Aggarwal, B. B. Curcumin Potentiates Antitumor Activity of Gemcitabine in an Orthotopic Model of Pancreatic Cancer through Suppression of Proliferation, Angiogenesis, and Inhibition of Nuclear Factor- $\kappa \mathrm{B}-$ Regulated Gene Products. Cancer Res. 2007, 67, 38533861.

(26) Li, Y.; Wang, P.; Chen, X.; Hu, J.; Liu, Y.; Wang, X.; Liu, Q. Activation of microbubbles by low-intensity pulsed ultrasound enhances the cytotoxicity of curcumin involving apoptosis induction and cell motility inhibition in human breast cancer MDA-MB-231 cells. Ultrason. Sonochem. 2016, 33, 26-36.

(27) Barik, A.; Priyadarsini, K. I.; Mohan, H. Photophysical Studies on Binding of Curcumin to Bovine Serum Albumin. Photochem. Photobiol. 2003, 77, 597-603.

(28) Ge, Y. S.; Jin, C.; Song, Z.; Zhang, J. Q.; Jiang, F. L.; Liu, Y. Multi-spectroscopic analysis and molecular modeling on the interaction of curcumin and its derivatives with human serum albumin: A comparative study. Spectrochim. Acta, Part A 2014, 124, 265-276.

(29) Kunwar, A.; Barik, A.; Pandey, R.; Priyadarsini, K. I. Transport of liposomal and albumin loaded curcumin to living cells: An absorption and fluorescence spectroscopic study. Biochim. Biophys. Acta, Gen. Subj. 2006, 1760, 1513-1520.

(30) Feshitan, J. A.; Chen, C.; Kwan, J. J.; Borden, M. A. Microbubble size isolation by differential centrifugation. J. Colloid Interface Sci. 2009, 329, 316-324.

(31) Upadhyay, A.; Dalvi, S. V. Synthesis, Characterization and Stability of BSA-Encapsulated Microbubbles. RSC Adv. 2016, 1501615026 .

(32) Hu, Y.; Wan, J. M. F.; Yu, A. C. H. Membrane Perforation and Recovery Dynamics in Microbubble-Mediated Sonoporation. Ultrasound Med. Biol. 2013, 39, 2393-2405.

(33) Suzuki, R.; Klibanov, A. L. Co-administration of Microbubbles and Drugs in Ultrasound-Assisted Drug Delivery: Comparison with DrugCarrying Particles; Springer International Publishing: Cham, 2016; pp 205-220.

(34) Sahoo, B. K.; Ghosh, K. S.; Dasgupta, S. Investigating the binding of curcumin derivatives to bovine serum albumin. Biophys. Chem. 2008, 132, 81-88.

(35) Upadhyay, A.; Dalvi, S. V.; Gupta, G.; Khanna, N. Effect of PEGylation on performance of protein microbubbles and its comparison with lipid microbubbles. Mater. Sci. Eng., C 2017, 71, $425-430$. 